\title{
Validation of the GOME-2 Absorbing Aerosol Height product using elevated layer top height obtained from Thessaloniki EARLINET station
}

\author{
Konstantinos Michailidis ${ }^{1}$, Nikolaos Siomos ${ }^{1}$, Dimitris S. Balis ${ }^{1}$, Maria-Elissavet Koukouli ${ }^{1}$ \\ Kalliopi-Artemis Voudouri ${ }^{1}$, Tuinder Olaf ${ }^{2}$, Gijsbert Tilstra ${ }^{2}$, Wang Ping ${ }^{2}$ \\ ${ }^{1}$ Laboratory of Atmospheric Physics, Physics Department, Aristotle University of Thessaloniki, Greece \\ ${ }^{2}$ Royal Netherlands Meteorological Institute (KNMI), De Bilt, the Netherlands \\ komichai@physics.auth.gr
}

\begin{abstract}
The purpose of this research is to investigate the ability of GOME-2 instrument on board on the MetOpA and MetOpB platforms, to deliver accurate geometrical features of lofted aerosol layers over the area of Thessaloniki. For this purpose, we use ground-based lidar data from the Thessaloniki lidar station that belongs to EARLINET network. Results of the validation between absorbing aerosol height (AAH) from GOME-2 sensor and THELISYS lidar dataset products will be presented.
\end{abstract}

\section{INTRODUCTION}

Aerosols affect the Earth's radiation budget directly by interacting with solar and terrestrial radiation and indirectly by affecting cloud processes, having a large impact on air quality. Such effects depend on the optical properties of the aerosols and their vertical distribution in the atmosphere. Knowledge of the aerosol layer height, ALH, is essential for understanding the impact of aerosols on the climate system. Groundbased observations are important to verify the accuracy and validity of satellite observations and model-based results. The purpose of validation is to detect biases in the comparison of space-borne absorbing aerosol height, AAH, products with independent ground based observations and establish the accuracy levels of such. Lidar instruments can provide aerosol profile information such as the backscatter and extinction coefficients at different wavelengths which are representative of the aerosol load, with a vertical resolution of a few meters. In this study we use data from satellite GOME-2 instrument and ground based lidar system located in Thessaloniki, Greece.

\section{DATA AND METHODOLOGY}

\subsection{THELISYS LIDAR}

Thessaloniki lidar system (THELISYS) is located at the Laboratory of Atmospheric Physics (LAP) $\left(40.5^{\circ} \mathrm{N}, 22.9^{\circ} \mathrm{E}, 50 \mathrm{~m}\right.$ above sea level) in Aristotle University of Thessaloniki (AUTH). THELISYS has been in operation since 2000 and is part of the European Aerosol Lidar Network (EARLINET). The European Aerosol Research Lidar Network has coordinated ground-based lidar activities on the European continent, and it holds a comprehensive database of European lidar data sets giving information on the horizontal, vertical and temporal distribution of aerosols on a continental scale [1]. The THELISYS lidar dataset used in our study includes vertical profiles of the aerosol extinction coefficient at $355 \mathrm{~nm}$ and 532nm, and the aerosol backscatter coefficient at $355 \mathrm{~nm}, 532 \mathrm{~nm}$, and $1064 \mathrm{~nm}$. Measurements are typically performed every Monday and Thursday according to the EARLINET schedule of data acquisition. All lidar profiles are publicly available on the EARLINET database [2] (www.earlinet.org). The time period between 2007 and 2018 is selected, so as to perform this validation study.

\subsection{GOME-2 /METOP}

In this study we use data from GOME-2 on board the MetOp-A and MetOp-B satellite platforms [3]. The GOME-2 instrument is a nadir looking and scanning UV-VIS spectrometer on board the METOP-A and METOP-B satellite platforms since 2006 and 2012 respectively that measures backscattered solar light. GOME-2 is comprised of four main optical channels of 1024 pixels 
giving in total 4096 spectral channels for a range of 240-790 nm and a spectral resolution of 0.26$0.51 \mathrm{~nm}$, with a ground pixel size $80 \times 40 \mathrm{~km}$, a total of 24 pixels in the forward scan, on a $1920 \mathrm{~km}$ of swath width. MetOp satellites are flying in sunsynchronous orbits with an approximate equator crossing time, around 09:30LT (descending node) and repeat cycle of 29 days. Data from GOME-2 (MetOpA and MetOpB) have been processed by the Royal Netherlands Meteorological Institute (KNMI) as part of the EUMETSAT Satellite Application Facility on Atmopsheric Composition Monitoring (https://acsaf.org/)

The absorbing aerosol index (AAI) derived from UV reflectances derived from the 340/380nm wavelength pair, is an operational product of the GOME-2 instrument [6]. The AAI product indicates the presence of elevated absorbing aerosols in the Earth's atmosphere. Aerosol types that are mostly encountered in this region are desert dust and aerosols from biomass burning and volcanic eruption events. A positive value for the AAI can only be explained by the presence of absorbing aerosols. Whenever the AAI is greater or equal than 2, the amount of observing aerosol is considered sufficient to result in a reliable retrieval of the AAH from satellite data [7]. Furthermore, AAI is sensitive to clouds therefore it is derived for both cloud free and cloudy scenes [8]. Factors such as sunglint, solar eclipses, surface height, and scattering geometry have to be taken into account as they can lead to abnormal $\mathrm{AAI}$ and AAH values [5].

\subsection{METHODOLOGY}

The time period from January 2007 to August 2018 is selected for the comparison between satellite (GOME-2) and ground-based Absorbing Aerosol Height (AAH). Aerosol geometrical properties carry information about the structure of lidar profiles such as PBL height and lofted aerosol layers, including vertical profiles of the aerosol extinction coefficient at $355 \mathrm{~nm}$, and the aerosol backscatter coefficient at 355nm, 532nm and $1064 \mathrm{~nm}$. The THELISYS data analysis, for lidar dataset, is based on the methodology of [4] that applies the wavelet covariance transform (WCT) to the raw lidar data in order to extract geometrical characteristics like PBL and cloud boundaries. We used this method in the case of lofted layers and we have chosen to identify the three major lofted layers with the largest contribution to the vertical profile. The GOME2 AAH product is provided directly by KNMI. The collocation of AAH satellite product have been restricted to an area of $300 \mathrm{~km}$ radius around Thessaloniki EARLINET station. The closest measurement in time has been selected for each overpass observation, within the limits set by the spatial collocation criteria. Since the satellite can detect only the top of the upper layer, the maximum value of the lidar features is selected per measurement for the comparison. In Figure 1, we present the spatial coverage for AAH collocated satellite product as derived from the comparison with ground based lidar measurements, at $6 \mathrm{~h}$ temporal interval. The concentric red circles denote regions of 100, 200, $300 \mathrm{~km}$ from the location of THELISYS lidar system.

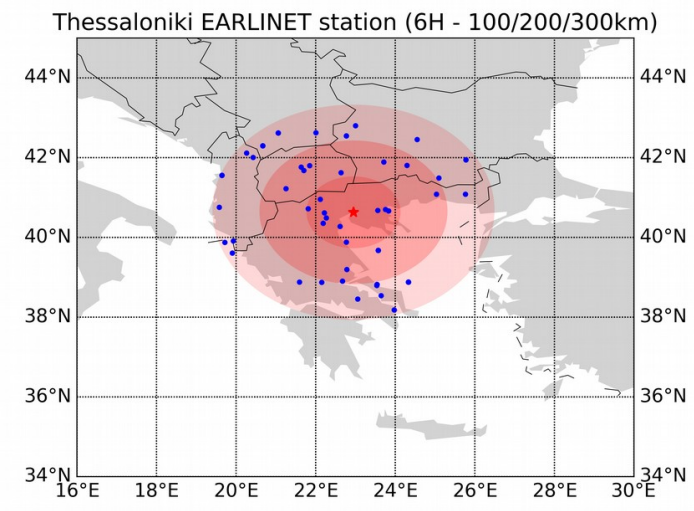

Figure 1: The concentric red circles denote regions of 100, 200, $300 \mathrm{~km}$ from the location of THELISYS lidar system (red asterisk).

\section{RESULTS}

In Figure 2, we show the AAH timeseries from the GOME-2 satellite measurements in blue and THELISYS observations in orange. In our data analysis we set as spatial criterion for coincidence over Thessaloniki, the value of $300 \mathrm{~km}$. We notice that there are more satellite measurements than the ground lidar. This difference is due to the fact that satellite sampling is daily, while lidar measurements usually occur two days a week for a short time period. Gaps occurring in the time 
series in terms of lidar measurements are due to cases where lidar was unable to measure because of presence of clouds. Especially, during the winter months it seems there is a limitation of lidar measurements. Apart from cloudy conditions, due to hardware limitations it is not possible for the lidar to operate during days with strong winds. There are quite large values for the height products. For satellite observations the maximum values reach $15 \mathrm{~km}$. This product is being retrieved can never be larger than $15 \mathrm{~km}$. A value of $15 \mathrm{~km}$ indicates that the real aerosol layer is at $15 \mathrm{~km}$ or higher.

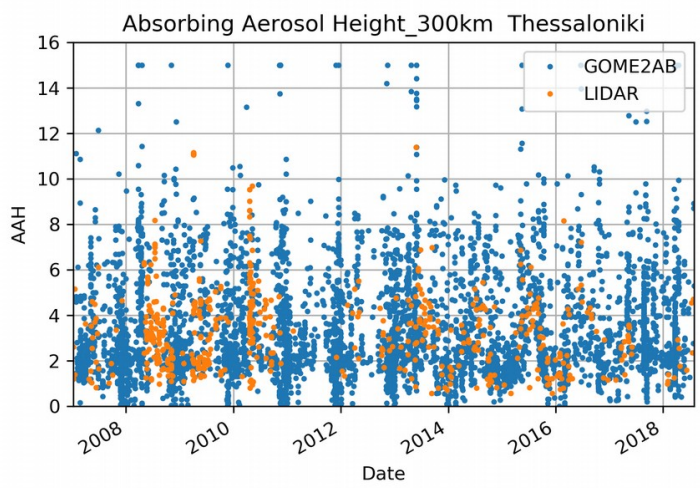

Figure 2: Timeseries of the GOME2 (blue) on MetOpA and MetOpB and the lidar (orange) dataset.

In Figure 3, a histogram depicting the absolute bias between of two AAH products is presented. 67 common cases for the period 2007 to 2018 were identified, with a mean bias value $0.28 \mathrm{~km}$, standard deviation of $2.8 \mathrm{~km}$ and a rather symmetric distribution function.

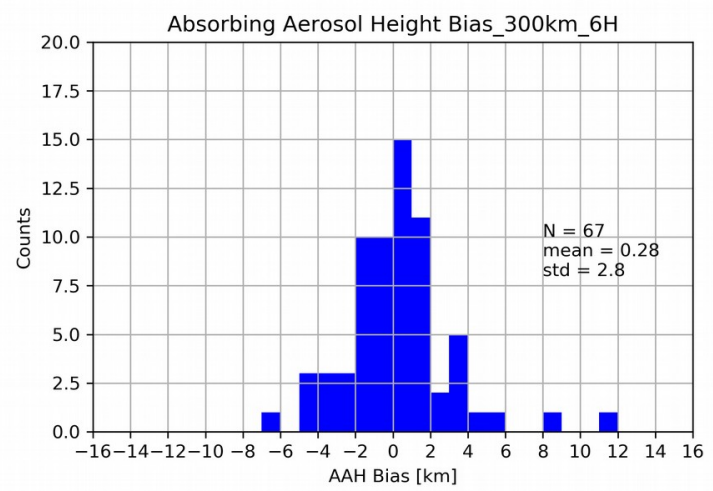

Figure 3: Histogram of the absolute bias between the satellite AAH and lidar upper layer top for the co-located cases .

Furthermore, a scatterplot of the collocated common layers $(300 \mathrm{~km} \mathrm{\&} 6 \mathrm{H})$ is presented in
Figure 4. The correlation coefficient for the collocated values is 0.197 . We notice that for values up to $3 \mathrm{~km}$ there is good agreement between the two datasets, while for measurements larger than $3 \mathrm{~km}$ the dispersion increases. Cases that exhibit large absolute and relative biases will be studied separately in order to identify the source of the discrepancies.

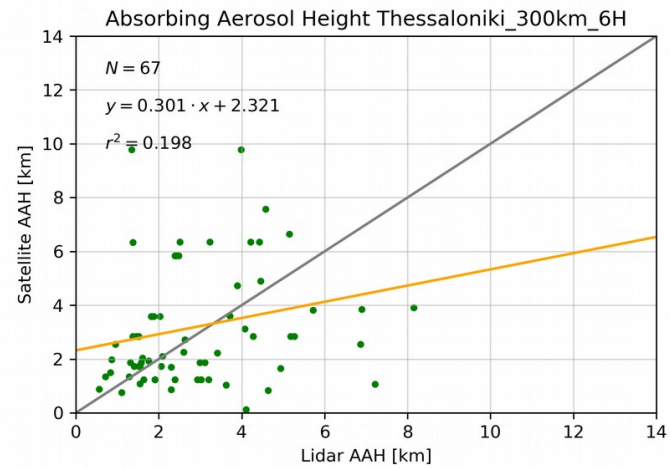

Figure 4: Scatterplot of the Lidar (THELISYS) AAH against the satellite AAH.

\section{CONCLUSIONS}

The time period from January 2007 to August 2018 is selected for the comparison between GOME-2 MetOpA and MetOpB and groundbased Lidar Absorbing Aerosol Height (AAH). Overall, the agreement between the lidar and satellite AAH product is quite promising, with a mean bias of $0.28 \pm 2.8 \mathrm{~km}$. In the future, the sensitivity of the bias to the spatial search radius, product quality flag are going to be examined. Also, studies that focus on the climatological circulation patterns will reveal information on the seasonal variations of the geometrical and optical properties that are observed. Study of cloud effects on the comparison of the two products will give answers about uncertainties that result in the calculation of the products. Furthermore, other lidar stations that are part of the EARLINET network will be included in the comparison for further validation.

\section{ACKNOWLEDGEMENTS}

We acknowledge support of this work by the project "PANhellenic infrastructure for Atmospheric Composition and climatE change" 
(MIS 5021516) which is implemented under the Action "Reinforcement of the Research and Innovation Infrastructure", funded by the Operational Programme "Competitiveness, Entrepreneurship and Innovation" (NSRF 20142020) and co-financed by Greece and the European Union (European Regional Development Fund). The data of the GOME-2 Absorbing Aerosol Index are provided by KNMI in the framework of the EUMETSAT Satellite Application Facility on Atmospheric Composition (AC SAF).

\section{REFERENCES}

[1] Balis, D., Koukouli, M.-E., Siomos, N., Dimopoulos, S., Mona, L., Pappalardo, G., Marenco, F., Clarisse, L., Ventress, L. J., Carboni, E., Grainger, R. G., Wang, P., Tilstra, G., van der A, R., Theys, N., and Zehner, C.: Validation of ash optical depth and layer height retrieved from passive satellite sensors using EARLINET and airborne lidar data: the case of the Eyjafjallajökull eruption, Atmos. Chem. Phys., 16, 5705-5720, https://doi.org/10.5194/acp-165705-2016, 2016

[2] Pappalardo, G., Amodeo, A., Apituley, A., Comeron, A., Freudenthaler, V., Linné, H., Ansmann, A., Bösenberg, J., D'Amico, G., Mattis, I., Mona, L., Wandinger, U., Amiridis, V., AladosArboledas, L., Nicolae, D., and Wiegner, M.: EARLINET: towards an advanced sustainable European aerosol lidar network, Atmos. Meas. Tech., 7, 2389-2409, https://doi.org/10.5194/amt-7-2389-2014, 2014.

[3] Hassinen, S., Balis, D., Bauer, H., Begoin, M., Delcloo, A., Eleftheratos, K., Gimeno Garcia, S., Granville, J., Grossi, M., Hao, N., Hedelt, P., Hendrick, F., Hess, M., Heue, K.-P., Hovila, J., Jønch-Sørensen, H., Kalakoski, N., Kauppi, A., Kiemle, S., Kins, L., Koukouli, M. E., Kujanpää, J., Lambert, J.-C., Lang, R., Lerot, C., Loyola, D., Pedergnana, M., Pinardi, G., Romahn, F., van Roozendael, M., Lutz, R., De Smedt, I., Stammes, P., Steinbrecht, W., Tamminen, J., Theys, N., Tilstra, L. G., Tuinder, O. N. E., Valks, P., Zerefos, C., Zimmer, W., and Zyrichidou, I.: Overview of the O3M SAF GOME-2 operational atmospheric composition and UV radiation data products and data availability, Atmos. Meas. Tech., 9, 383407, https://doi.org/10.5194/amt-9-383-2016, 2016.

[4] Siomos, N., Balis, D. S., Voudouri, K. A., Giannakaki, E., Filioglou, M., Amiridis, V., Papayannis, A., and Fragkos, K.: Are EARLINET and AERONET climatologies consistent? The case of Thessaloniki, Greece, Atmos. Chem. Phys., 18, 11885-11903, https://doi.org/10.5194/acp-1811885-2018, 2018.

[5] M. de Graaf, P. Stammes, O. Torres, and R.B.A. Koelemeijer, Absorbing Aerosol Index: Sensitivity analysis, application to GOME and comparison with TOMS, J. Geophys. Res. 110, D010201, doi:10.1029/2004JD005178, 2005.

[6] Tilstra, L. G., O. N. E. Tuinder, and P. Stammes (2010), GOME-2 Absorbing Aerosol Index: statistical analysis, comparison to GOME-1 and impact of instrument degradation, in Proceedings of the 2010 EUMETSAT Meteorological Satellite Conference, EUMETSAT P.57, ISBN 978-92-9110-089-7, Cordoba, Spain.

[7] Tuinder, O. N. E. and L. G. Tilstra (2016), Near Real-Time, Offline and Data Set Aerosol Products - Product User Manual, Doc. No. O3MSAF/KNMI/PUM/002, Issue 1.61, 11 January 2016, KNMI, De Bilt, The Netherlands.

[8] Wang, P., O. N. E. Tuinder, L. G. Tilstra, M. de Graaf, and P. Stammes (2012), Interpretation of FRESCO cloud retrievals in case of absorbing aerosol events, Atmos. Chem. Phys., 12(19), 9057-9077, doi:10.5194/acp-12-9057-2012. 